\title{
TIPOS DE OPORTUNIDADES NO EMPREENDEDORISMO INTERNACIONAL ${ }^{\mathrm{i}}$
}

DOI: $10.14211 / 41187$

Artigo recebido em: 29/09/2014.

Artigo aprovado em: 30/12/2014.

Yákara Vasconcelos Pereira Leite - Universidade Federal Rural do Semi-Árido ${ }^{1}$ Walter Fernando Araújo de Moraes - Universidade Federal de Pernambuco ${ }^{2}$ Viviane Santos Salazar - Universidade Federal de Pernambuco ${ }^{3}$

Resumo: Esta pesquisa teve o objetivo de analisar os tipos de oportunidades no empreendedorismo internacional. Para alcançá-lo, um estudo de múltiplos casos qualitativo foi desenvolvido. A entrevista semiestruturada foi a principal via para coletar dados com 30 gestores e consultores. O software ATLAS.ti apoiou a análise de conteúdo dos dados. Foram identificados dois tipos de oportunidades, a internacional e nacional. Tal resultado complementa o que vem sendo investigado sobre oportunidades no empreendedorismo internacional, que se limita as do tipo internacional. Além disso, percebe-se que a intermitência da exploração de oportunidades no processo de internacionalização é mais uma característica da dimensão.

Palavras-chave: Empreendedorismo internacional, oportunidades, exportadoras.

\section{TYPES OF OPPORTUNITIES IN INTERNATIONAL ENTREPRENEURSHIP}

Abstract: This research aimed to analyze the types of opportunities in international entrepreneurship. To achieve this, a study of multiple qualitative case was developed. A semi structured interview was the main route to collect data with 30 managers and consultants. The ATLAS.ti software supported content analysis of the data. Two types of opportunities, both internationally and domestically were identified. This result complements what is being inquired about opportunities in international entrepreneurship, which is confined to the international brand. Moreover, it is noticed that the intermittency of the opportunities in the internationalization process is more a feature of size.

Keywords: International Entrepreneurship, opportunities, exporters.

\footnotetext{
${ }^{1}$ E.mail: yakarav@gmail.com - Endereço: Av. Francisco Mota, 572, Bairro Costa e Silva, Mossoró RN, CEP: 59.625-900.

2 E.mail: walter.moraes@ufpe.br

${ }^{3}$ E.mail: viviane_salazar@yahoo.com.br
}

LEITE, Y. V. P.; MORAES, W. F. A.; SALAZAR, V. S. Tipos de oportunidades no empreendedorismo internacional. Revista de Empreendedorismo e Gestão de Pequenas Empresas, v. 4, n. 1, 2015. 
Introdução

A exploração de oportunidades internacionais é um dos elementos-chave do empreendedorismo internacional (El). Ao identificar a oportunidade no ambiente externo, o dirigente geralmente enfrenta riscos para explorá-la, com o objetivo de firmar-se no mercado internacional.

Em relação às oportunidades no mercado internacional, Zahra e George (2002) defendem que a sua exploração pode ser influenciada pela criatividade empreendedora de vários membros do time gerencial. Enquanto que para Dimitratos e Plakoyiannaki (2003), a identificação de oportunidades é insuficiente e a habilidade de explorá-las é essencial. Esse argumento é semelhante ao defendido por Oviatt e McDougall (2005).

Ressalta-se que a exploração de oportunidades segue em meio ao processo do empreendedorismo internacional. Dimitratos e Plakoyiannaki (2003) reconhecem o El como sendo um processo que ocorre em determinado contexto, aproximandose do entendimento de Mtigwe (2006).

A questão processual do empreendedorismo internacional é percebida por autores contemporâneos. Há pesquisadores que entendem o El como um processo em si (COOMBS; SADRIEH; ANNAVARJULA, 2009), podendo também ser motivado pela busca para conquistar a criação de valor (MTIGWE, 2006) e descobrir oportunidades (ZAHRA; GEORGE, 2002). É um fenômeno que tende a ser melhor observado em um período mais longo de tempo devido ao seu caráter processual (LEITE; MORAES, 2014).

Nessa perspectiva processual, o contexto é fundamental nos estudos de empreendedorismo internacional. A identificação e a exploração de oportunidades são dinâmicas e dependentes da situação ambiental (VENKATARAMAN et al., 2012) e mostram-se como componentes que traz um entendimento mais harmônico e completo do El.

Desse modo, diante de sua relevância para o El, o artigo tem por objetivo analisar os tipos de oportunidades no empreendedorismo internacional. Portanto, o artigo está organizado em cinco seções. Após esta introdução, o referencial teórico é 
apresentado, seguido dos procedimentos metodológicos, resultados e considerações finais.

\section{Oportunidades internacionais}

A identificação e a exploração de oportunidades no ambiente externo requerem habilidade e visão por parte dos dirigentes. O gestor que reconhece uma oportunidade precisa ter ou desenvolver capacidade para explorá-la, no sentido de não perder o momento-chave de alavancar e manter o desempenho econômico empresarial.

O reconhecimento de oportunidades depende da relação entre 0 empreendedor e o contexto (VENKATARAMAN et al., 2012). Embora seja recomendável se antecipar para melhor explorá-las, as oportunidades podem surgir independentemente de atitudes proativas do empreendedor (SCHWEIZER; VAHLNE; JOHANSON, 2010). Em resposta ao ambiente externo, os administradores fazem opções estratégicas mesmo que precisem enfrentar as restrições ambientais. $\mathrm{Na}$ abordagem da escolha estratégica, os dirigentes (líderes ou coalizões dominantes) monitoram o ambiente considerado relevante (CHILD, 1972) para identificar oportunidades e formular estratégias em resposta às mudanças ambientais.

Child e Smith (1987) entendem que o contexto externo está composto pelo ambiente objetivo e o ambiente subjetivo. O primeiro é formado pelos acontecimentos reais da mudança, o segundo, contudo, pelas percepções e interpretações acerca do ambiente objetivo. Essas ideias estão em consonância com o processo de percepção dos gestores, anteriormente proposto por Child (1972), e com os pressupostos do empreendedorismo internacional. Isto porque encontrar a oportunidade não é suficiente, é preciso interpretar os significados (JONES; COVIELLO; TANG, 2011).

Smircich e Stubbart (1985) sugerem que essas representações do ambiente objetivo podem ter interpretações distorcidas. Na busca de minimizá-las, os autores definem o ambiente declarado (enacted) como aquele que requer esforços intelectuais dos participantes para gerar sentido (comum) dentro das empresas. 
Acredita-se que os líderes não podem considerar-se excluídos da dinâmica ambiental, pois eles também promovem tendências, uma vez que fazem parte da elaboração das estratégias.

A partir da interação com o ambiente, o empreendedor toma a decisão de explorar oportunidades. Esse processo depende da natureza das oportunidades (expectativa de retorno elevado) e das diferenças individuais (custo de oportunidade) (SHANE; VENKATARAMAN, 2000). Os empreendedores procuram oportunidades viáveis que passem valor ao cliente para ter retornos financeiros elevados. Venkataraman et al. (2012, p. 26) complementam ao afirmar que "as oportunidades são, de fato, artefatos. Sua elaboração envolve a transformação do mundo existente em novas possibilidades".

A ênfase na oportunidade é característica da escola gerencial de empreendedorismo e o processo de sua exploração também está condicionado às habilidades do dirigente (PETERSON, 1988). Hosmer (1982) explica que por meio do senso de direção pode-se coordenar e integrar o grupo conforme necessário para formular, implementar as estratégias e, principalmente, explorar as oportunidades.

A descentralização e o trabalho da equipe permitem que outros indivíduos tenham autonomia. Com isso, a visão empreendedora tem chances de ser ampliada para o grupo, o que facilita as ações em uma economia global (IRELAND; HITT, 1999).

O comércio internacional é, para Barney (2002), uma oportunidade de negócio na gestão estratégica. Muitas vezes, as imperfeições do mercado precisam ser identificadas pelo empreendedor (MCDOUGALL, 1989) para serem utilizadas em benefício da empresa. O papel do dirigente é essencial na internacionalização, conforme compartilhado por diferentes autores de negócios internacionais (JOHANSON; VAHLNE, 1977, 2009; VERNON, 1966). Ele pode explorar uma oportunidade por meio da transferência de eficiência (BARTLETT; GHOSHAL, 1987), da aprendizagem e conhecimento (BARTLETT; GHOSHAL, 1987; VERNON, 1966), da experiência (JOHANSON; VAHLNE, 1977, 2009), da mentalidade global (NUMMELA; SAARENKETO; PUUMALAINEN, 2004) e das networks (JOHANSON; VAHLNE, 2009). Assim, observa-se que a exploração de oportunidades depende das ações empreendedoras que viabilizam a internacionalização.

LEITE, Y. V. P.; MORAES, W. F. A.; SALAZAR, V. S. Tipos de oportunidades no empreendedorismo internacional. Revista de Empreendedorismo e Gestão de Pequenas 
Diante do exposto, percebe-se que o modo com que a ação empreendedora no processo de exploração ocorre faz diferença na iniciação e sustentação da internacionalização ao longo dos anos. O empreendedor está no centro dessa discussão, para explorá-las, utilizando a sua visão, mentalidade global, experiência, redes de relacionamentos e seu conhecimento.

\section{Procedimentos metodológicos}

Para investigar $0 \mathrm{El}$, é relevante considerar 0 processo de internacionalização. Desse modo, o fenômeno foi examinado retrospectivamente, de modo longitudinal, método indicado por Coviello e Jones (2004), Kiss, Danis e Cavusgil (2012) para os estudos de El.

Após o estudo de cada uma das empresas, considerou-se o exame entre os casos, denominando-se análise cruzada dos casos (MERRIAM, 1998; STAKE, 1995). O estudo de caso caracteriza-se por ser um tipo de pesquisa que se diferencia pela análise em profundidade (GODOY, 1995; MERRIAM, 1998; YIN, 2001) e podem existir diversos níveis de seleção (MERRIAM, 1998). Aqui, foram adotados intencionalmente quatro, a saber: região, segmento econômico, empresas e sujeitos.

$\mathrm{Na}$ primeira etapa, optou-se por estudar a região do semiárido brasileiro devido aos seguintes fatores: (i) área geográfica peculiar que pode gerar insights acadêmicos; (ii) dentre os nove Estados que a constitui, oito fazem parte do Nordeste, local carente de desenvolvimento de pesquisas e de recursos científicostecnológicos; (iii) por este trabalho fazer parte do grupo de pesquisa que vem envidando esforços para investigar empresas do Nordeste; e (iv) pelo compromisso que os pesquisadores possuem com a melhoria do semiárido.

Em uma segunda fase, observou-se nessa região o destaque da fruticultura na pauta de exportação brasileira. Entre janeiro e setembro de 2011, as frutas foram responsáveis pelo montante exportado de US\$ 206 milhões (MDIC, 2011), valor significativo para a região. Diante do desempenho econômico e da vocação natural local para esse tipo de cultivo, determinou-se estudar empresas do segmento da fruticultura. 
$\mathrm{Na}$ terceira etapa, estimou-se a seleção de empresas que atuam no segmento da fruticultura em consonância com as recomendações de Eisenhardt (1989). Quatro empresas representantes dos estados da Bahia, Ceará, Pernambuco e Rio Grande do Norte foram selecionadas. Os dados coletados entre janeiro e setembro de 2011 indicam que esses estados são responsáveis por aproximadamente $100 \%$ do total de frutas exportadas no semiárido (MDIC, 2011).

Os sujeitos sociais e os casos foram selecionados pelo critério de conveniência devido ao acesso às informações (MERRIAM, 1998). Quanto à identificação das empresas, os seguintes parâmetros foram considerados: (a) estar localizada nas cidades de maior volume de exportação de frutas; (b) ter o centro de decisões gerenciais em algum dos municípios do semiárido; (c) possuir valor de exportação na faixa entre US\$1 e US\$ 100 milhões; (d) ter no mínimo oito anos de atividade no comércio exterior devido à análise longitudinal; (e) ter se originado (fundação) no semiárido brasileiro; (f) ser considerada pelo SEBRAE como empresa de grande porte, na classificação definida em função do número de pessoas ocupadas na firma (SEBRAE, 2011); e (g) ter acesso às informações.

O ano de abertura, localização, quantidade de funcionários empregados no período de safra, faixa de valor exportado em 2011 e a sigla das empresas selecionadas são apresentados no quadro 1. A Special Fruit é a firma com mais tempo de mercado ao passo que a Ara Agrícola possui apenas oito anos de atividade. A Agrícola Famosa emprega 5.000 pessoas e a Agro Melão 500, ambas têm o melão como principal produto exportado.

\begin{tabular}{|c|c|c|c|c|}
\hline \multirow[b]{2}{*}{ CARACTERÍSTICAS } & \multicolumn{4}{|c|}{ EMPRESAS } \\
\hline & $\begin{array}{l}\text { AGRÍCOLA } \\
\text { FAMOSA }\end{array}$ & AGRO MELÃO & $\begin{array}{l}\text { SPECIAL } \\
\text { FRUIT }\end{array}$ & $\begin{array}{l}\text { ARA } \\
\text { AGRÍCOLA }\end{array}$ \\
\hline Abertura & 1995 & 1997 & 1982 & 2004 \\
\hline Localização & Icapuí-CE & Mossoró-RN & $\begin{array}{l}\text { Juazeiro- } \\
\text { BA }\end{array}$ & Petrolina-PE \\
\hline $\begin{array}{l}\text { Número de } \\
\text { funcionários (safra) }\end{array}$ & 5.000 & 500 & 1.700 & 1.000 \\
\hline $\begin{array}{lll}\text { Faixa de } & \text { valor } \\
\text { exportado em } 2011\end{array}$ & $\begin{array}{l}\text { Entre US } \$ 50 \\
\text { e US\$ } 100 \\
\text { milhões }\end{array}$ & $\begin{array}{l}\text { Entre US\$1 e US\$ } \\
10 \text { milhões }\end{array}$ & $\begin{array}{l}\text { Entre US\$ } \\
10 \text { e US\$ } \\
50 \text { milhões }\end{array}$ & $\begin{array}{lr}\text { Entre US\$ } 10 \\
\mathrm{e} \quad \text { US\$ } & 50 \\
\text { milhões } & \\
\end{array}$ \\
\hline $\begin{array}{l}\text { Principais produtos } \\
\text { exportados }\end{array}$ & Melão & Melão & $\begin{array}{ll}\text { Uva } & \mathrm{e} \\
\text { manga } & \end{array}$ & $\begin{array}{l}\text { Uva sem } \\
\text { sementes }\end{array}$ \\
\hline $\begin{array}{ll}\text { Sigla adotada no } \\
\text { estudo }\end{array}$ & $\overline{\mathrm{AF}}$ & $\overline{\mathrm{AM}}$ & $\overline{S F}$ & ARA \\
\hline
\end{tabular}

LEITE, Y. V. P.; MORAES, W. F. A.; SALAZAR, V. S. Tipos de oportunidades no empreendedorismo internacional. Revista de Empreendedorismo e Gestão de Pequenas 
QUADRO 1 - Apresentação sintética dos casos selecionados

Fonte: Elaboração dos autores (2012).

Ressalta-se que os representantes da Agrícola Famosa, Special Fruit e Ara Agrícola autorizaram a divulgação do nome da empresa na pesquisa mediante assinatura do termo de consentimento. A única exceção é a exportadora de Mossoró-RN. Portanto, para garantir a confidencialidade exigida pelo gestor, a empresa está aqui nomeada de Agro Melão.

Em relação aos respondentes, privilegiaram-se aqueles sujeitos sociais que dispunham de informações sobre a dinâmica competitiva da região do semiárido, a respeito do segmento no qual atuam e sobre as decisões de investimentos e de implementação de estratégias internacionais. A quantidade de entrevistados foi definida quando as categorias atingiram o ponto de saturação adequado para responder aos objetivos da pesquisa (PAIVA JÚNIOR; LEÃO; MELLO, 2011), totalizando 30 sujeitos sociais.

Por ser um estudo qualitativo, tendo em vista a natureza do fenômeno, diferentes técnicas de coleta de dados foram utilizadas. Dentre elas, pode-se citar a entrevista semiestruturada, a análise de documentos e bibliográfica (TAYLOR; BOGDAN, 1984).

As entrevistas aconteceram em dois momentos distintos, foram gravadas e transcritas, perfazendo 1.242 minutos no total e uma média de 40 minutos por entrevistado. Após a primeira coleta de dados primários ( $1^{\text {a }}$ etapa), as informações foram analisadas de modo exploratório. Assim, foram identificadas poucas incongruências e contradições, motivando o retorno ao campo para validar e consolidar a interpretação dos dados. Por essa técnica, cada um dos 30 respondentes foi entrevistado uma vez, apenas o gerente comercial de exportação da Agrícola Famosa foi entrevistado novamente.

O quadro 2 expõe informações detalhadas sobre a etapa em que cada sujeito participou, o código do entrevistado (remete ao polo que está inserido com o número de ordem da coleta), a descrição (indicando a empresa e sua função), a formação (grau escolar), o tempo de atuação na organização, a identidade no ATLAS.ti (código gerado no sistema), a data de realização da coleta dos dados e tempo de entrevista. 
No período entre junho e outubro de 2012, as entrevistas aconteceram em Mossoró-RN, em fazendas localizadas na divisa entre $\mathrm{RN}$ e $\mathrm{CE}$, e nas cidades de Petrolina-PE, Juazeiro-BA e Recife-PE. A maioria aconteceu individualmente, exceto duas que foram em grupo, o P6 que contou com a participação de três indivíduos, os entrevistados 6,7 e 8 e o P16, com os respondentes 18 e 19.

\begin{tabular}{|c|c|c|c|c|c|c|c|}
\hline Etapa & $\begin{array}{l}\text { Código do } \\
\text { entrevistado }\end{array}$ & Descrição & Formação & $\begin{array}{l}\text { Tempo } \\
\text { na org. }\end{array}$ & $\begin{array}{l}\text { Id. } \\
\text { Atlas }\end{array}$ & Data & Tempo \\
\hline \multirow{16}{*}{ 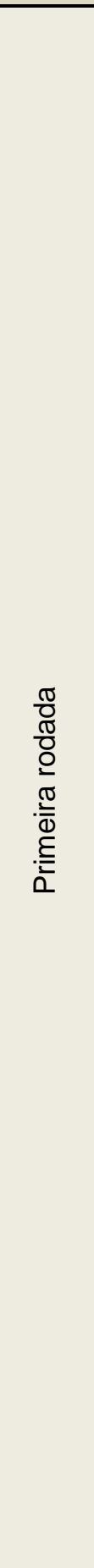 } & $\begin{array}{c}\text { Entrevistado } \\
\text { RNeCE } 1\end{array}$ & $\begin{array}{l}\text { SEBRAE Mossoró } \\
\text { - Ger. de projeto }\end{array}$ & $\begin{array}{c}\text { Engenheiro } \\
\text { Agrônomo }\end{array}$ & -------- & P1 & $\begin{array}{l}04 / 06 \\
/ 2012 \\
\end{array}$ & $31 \mathrm{~m}$. \\
\hline & $\begin{array}{c}\text { Entrevistado } \\
\text { RNeCE } 2\end{array}$ & $\begin{array}{l}\text { Agrícola Famosa - } \\
\text { G. Comercial de } \\
\text { Exportação }\end{array}$ & Economista & $\begin{array}{l}2007- \\
\text { atual }\end{array}$ & P2 & $\begin{array}{l}11 / 06 \\
/ 2012\end{array}$ & $68 \mathrm{~m}$. \\
\hline & $\begin{array}{c}\text { Entrevistado } \\
\text { RNeCE } 3\end{array}$ & $\begin{array}{l}\text { Ex-funcionário da } \\
\text { Agrícola Famosa } \\
\text { (setor de } \\
\text { exportação) }\end{array}$ & $\begin{array}{c}\text { Grad. } \\
\text { Administraçã } \\
\text { o (cursando) }\end{array}$ & $\begin{array}{l}2007- \\
2009\end{array}$ & P3 & $\begin{array}{l}18 / 06 \\
/ 2012\end{array}$ & $66 \mathrm{~m}$ \\
\hline & $\begin{array}{l}\text { Entrevistado } \\
\text { RNeCE } 4\end{array}$ & $\begin{array}{c}\text { Agrônomo da Agro } \\
\text { Melão } \\
\text { (Responsável } \\
\text { Técnico) }\end{array}$ & $\begin{array}{l}\text { Engenheiro } \\
\text { Agrônomo }\end{array}$ & $\begin{array}{l}2003- \\
\text { atual }\end{array}$ & P4 & $\begin{array}{l}20 / 06 \\
/ 2012\end{array}$ & $33 m$. \\
\hline & $\begin{array}{l}\text { Entrevistado } \\
\text { RNeCE } 5\end{array}$ & $\begin{array}{c}\text { Representante do } \\
\text { grupo dos } \\
\text { japoneses }\end{array}$ & $\begin{array}{l}\text { Engenheiro } \\
\text { Agrônomo }\end{array}$ & $\begin{array}{l}2002- \\
\text { atual }\end{array}$ & P5 & $\begin{array}{l}21 / 06 \\
/ 2012\end{array}$ & $40 \mathrm{~m}$ \\
\hline & $\begin{array}{l}\text { Entrevistada } \\
\text { RNeCE } 6\end{array}$ & $\begin{array}{l}\text { Administrativo } \\
\text { Agro Melão }\end{array}$ & $\begin{array}{c}\text { Grad. } \\
\text { Administraçã } \\
\text { o (cursando) }\end{array}$ & $\begin{array}{l}2008- \\
\text { atual }\end{array}$ & \multirow{3}{*}{ P6 } & \multirow{3}{*}{$\begin{array}{l}21 / 06 \\
/ 2012\end{array}$} & \multirow{3}{*}{$48 m}$. \\
\hline & $\begin{array}{l}\text { Entrevistada } \\
\text { RNeCE } 7\end{array}$ & $\begin{array}{l}\text { Administrativo } \\
\text { Agro Melão }\end{array}$ & $\begin{array}{l}\text { Ciências } \\
\text { contábeis }\end{array}$ & $\begin{array}{l}2010- \\
\text { atual }\end{array}$ & & & \\
\hline & $\begin{array}{c}\text { Entrevistado } \\
\text { RNeCE } 8\end{array}$ & $\begin{array}{l}\text { Administrativo } \\
\text { Agro Melão }\end{array}$ & $\begin{array}{l}\text { Ciências } \\
\text { contábeis }\end{array}$ & $\begin{array}{l}2010- \\
\text { atual }\end{array}$ & & & \\
\hline & $\begin{array}{c}\text { Entrevistado } \\
\text { RNeCE } 9 \\
\end{array}$ & $\begin{array}{l}\text { Presidente da } \\
\text { COEX }\end{array}$ & Advogado & $\begin{array}{l}2002- \\
\text { atual }\end{array}$ & P7 & $\begin{array}{l}26 / 06 \\
/ 2012 \\
\end{array}$ & $46 \mathrm{~m}$ \\
\hline & $\begin{array}{l}\text { Entrevistado } \\
\text { RNeCE } 10\end{array}$ & $\begin{array}{c}\text { Agrícola Famosa - } \\
\text { Analista de } \\
\text { importação e } \\
\text { exportação }\end{array}$ & $\begin{array}{c}\text { Grad. } \\
\text { Administraçãa } \\
\text { o (cursando) }\end{array}$ & $\begin{array}{l}2008- \\
\text { atual }\end{array}$ & P8 & $\begin{array}{l}26 / 06 \\
/ 2012\end{array}$ & $28 \mathrm{~m}$. \\
\hline & $\begin{array}{c}\text { Entrevistado } \\
\text { RNeCE } 11\end{array}$ & $\begin{array}{l}\text { Agrícola Famosa - } \\
\text { sócio-fundador }\end{array}$ & Advogado & $\begin{array}{l}1995- \\
\text { atual }\end{array}$ & P9 & $\begin{array}{l}27 / 06 \\
/ 2012\end{array}$ & $31 \mathrm{~m}$. \\
\hline & $\begin{array}{c}\text { Entrevistado } \\
\text { RNeCE } 12\end{array}$ & $\begin{array}{c}\text { Agrícola Famosa - } \\
\text { novo sócio }\end{array}$ & $\begin{array}{l}\text { Engenheiro } \\
\text { Agrônomo }\end{array}$ & $\begin{array}{l}2009- \\
\text { atual }\end{array}$ & P10 & $\begin{array}{l}27 / 06 \\
/ 2012\end{array}$ & $11 \mathrm{~m}$ \\
\hline & $\begin{array}{c}\text { Entrevistado } \\
\text { RNeCE } 13\end{array}$ & $\begin{array}{l}\text { Agro Melão - } \\
\text { Gerente de } \\
\text { Exportação }\end{array}$ & Graduação & $\begin{array}{l}2005- \\
\text { atual }\end{array}$ & P11 & $\begin{array}{l}28 / 06 \\
/ 2012\end{array}$ & $33 \mathrm{~m}$. \\
\hline & $\begin{array}{c}\text { Entrevistado } \\
\text { RNeCE } 14\end{array}$ & $\begin{array}{l}\text { Agro Melão - } \\
\text { proprietário }\end{array}$ & $\begin{array}{c}\text { Engenheiro } \\
\text { Agrônomo }\end{array}$ & $\begin{array}{l}1997- \\
\text { atual }\end{array}$ & P12 & $\begin{array}{l}03 / 07 \\
/ 2012\end{array}$ & $23 \mathrm{~m}$ \\
\hline & $\begin{array}{c}\text { Entrevistado } \\
\text { RNeCE 15 } \\
\end{array}$ & $\begin{array}{l}\text { Agrícola Famosa - } \\
\text { sócio-fundador }\end{array}$ & $\begin{array}{c}\text { Segundo } \\
\text { grau }\end{array}$ & $\begin{array}{l}1995- \\
\text { atual }\end{array}$ & P13 & $\begin{array}{l}04 / 07 \\
/ 2012 \\
\end{array}$ & $37 \mathrm{~m}$. \\
\hline & $\begin{array}{c}\text { Entrevistada } \\
\text { PEeBA } 16\end{array}$ & $\begin{array}{l}\text { ARA Agrícola - } \\
\text { Gerente } \\
\text { Administrativo }\end{array}$ & $\begin{array}{l}\text { Ciência da } \\
\text { Computação }\end{array}$ & $\begin{array}{l}2010- \\
\text { atual }\end{array}$ & P14 & $\begin{array}{l}09 / 07 \\
/ 2012\end{array}$ & $59 \mathrm{~m}$ \\
\hline
\end{tabular}

LEITE, Y. V. P.; MORAES, W. F. A.; SALAZAR, V. S. Tipos de oportunidades no empreendedorismo internacional. Revista de Empreendedorismo e Gestão de Pequenas Empresas, v. 4, n. 1, 2015. 


\begin{tabular}{|c|c|c|c|c|c|c|c|}
\hline & $\begin{array}{l}\text { Entrevistado } \\
\text { PEeBA } 17\end{array}$ & $\begin{array}{l}\text { ARA Agrícola - } \\
\text { Gerente de } \\
\text { Campo }\end{array}$ & $\begin{array}{l}\text { Engenheiro } \\
\text { Agrônomo }\end{array}$ & $\begin{array}{l}2009- \\
\text { atual }\end{array}$ & P15 & $\begin{array}{l}09 / 07 \\
/ 2012\end{array}$ & $25 \mathrm{~m}$. \\
\hline & $\begin{array}{c}\text { Entrevistado } \\
\text { PEeBA } 18\end{array}$ & $\begin{array}{l}\text { EMBRAPA } \\
\text { Semiárido }\end{array}$ & Mestrado & & \multirow{2}{*}{ P16 } & \multirow{2}{*}{$\begin{array}{l}09 / 07 \\
/ 2012\end{array}$} & \multirow{2}{*}{$43 m$. } \\
\hline & $\begin{array}{c}\text { Entrevistado } \\
\text { PEeBA } 19\end{array}$ & $\begin{array}{l}\text { EMBRAPA } \\
\text { Semiárido }\end{array}$ & $\begin{array}{c}\text { Pós- } \\
\text { doutorado }\end{array}$ & ------. & & & \\
\hline & $\begin{array}{l}\text { Entrevistado } \\
\text { PEeBA } 20\end{array}$ & $\begin{array}{l}\text { SEBRAE Unidade } \\
\text { de Negócios } \\
\text { Sertão do São } \\
\text { Francisco }\end{array}$ & Especialista & $\begin{array}{l}2006- \\
\text { atual }\end{array}$ & P17 & $\begin{array}{l}10 / 07 \\
/ 2012\end{array}$ & $58 \mathrm{~m}$. \\
\hline & $\begin{array}{l}\text { Entrevistada } \\
\text { PEeBA } 21\end{array}$ & $\begin{array}{l}\text { SEBRAE Unidade } \\
\text { de Negócios } \\
\text { Sertão do São } \\
\text { Francisco }\end{array}$ & $\begin{array}{c}\text { Administrado } \\
\text { ra }\end{array}$ & & P18 & $\begin{array}{l}10 / 07 \\
/ 2012\end{array}$ & $23 \mathrm{~m}$. \\
\hline & $\begin{array}{c}\text { Entrevistado } \\
\text { PEeBA } 22\end{array}$ & VALEXPORT & Graduação & $\begin{array}{l}2003- \\
\text { atual }\end{array}$ & P19 & $\begin{array}{l}10 / 07 \\
/ 2012\end{array}$ & $52 \mathrm{~m}$. \\
\hline & $\begin{array}{c}\text { Entrevistado } \\
\text { PEeBA } 23\end{array}$ & $\begin{array}{l}\text { EMBRAPA } \\
\text { Semiárido }\end{array}$ & Doutor & ---------- & P20 & $\begin{array}{l}11 / 07 \\
/ 2012 \\
\end{array}$ & $50 \mathrm{~m}$. \\
\hline & $\begin{array}{l}\text { Entrevistada } \\
\text { PEeBA } 24\end{array}$ & $\begin{array}{l}\text { Special Fruit - } \\
\text { Gerente Comercial } \\
\text { de Exportacão }\end{array}$ & Especialista & $\begin{array}{l}2001- \\
\text { atual }\end{array}$ & P21 & $\begin{array}{l}11 / 07 \\
/ 2012\end{array}$ & $71 \mathrm{~m}$. \\
\hline & $\begin{array}{c}\text { Entrevistado } \\
\text { PEeBA } 25\end{array}$ & $\begin{array}{l}\text { Special Fruit - } \\
\text { proprietário }\end{array}$ & $\begin{array}{l}\text { Graduação } \\
\text { incompleta }\end{array}$ & $\begin{array}{l}1982- \\
\text { atual }\end{array}$ & P22 & $\begin{array}{l}11 / 07 \\
/ 2012\end{array}$ & $73 \mathrm{~m}$. \\
\hline & $\begin{array}{c}\text { Entrevistado } \\
\text { PEeBA } 26\end{array}$ & CODEVASF & Mestre & $\begin{array}{l}2005- \\
\text { atual }\end{array}$ & P23 & $\begin{array}{l}11 / 07 \\
/ 2012\end{array}$ & $67 \mathrm{~m}$. \\
\hline & $\begin{array}{c}\text { Entrevistado } \\
\text { PEeBA } 27\end{array}$ & $\begin{array}{l}\text { ARA Agrícola - } \\
\text { diretor (filho do } \\
\text { proprietário) }\end{array}$ & $\begin{array}{l}\text { Engenheiro } \\
\text { civil }\end{array}$ & $\begin{array}{l}2004- \\
\text { atual }\end{array}$ & P24 & $\begin{array}{l}12 / 07 \\
/ 2012\end{array}$ & $68 \mathrm{~m}$. \\
\hline & $\begin{array}{l}\text { Entrevistado } \\
\text { PEeBA } 28\end{array}$ & $\begin{array}{l}\text { ARA Agrícola - } \\
\text { gerente de } \\
\text { infraestrutura }\end{array}$ & $\begin{array}{l}\text { Engenheiro } \\
\text { elétrico }\end{array}$ & $\begin{array}{l}2008- \\
\text { atual }\end{array}$ & P25 & $\begin{array}{l}12 / 07 \\
/ 2012\end{array}$ & $26 \mathrm{~m}$. \\
\hline & $\begin{array}{c}\text { Entrevistado } \\
\text { PEeBA } 29\end{array}$ & $\begin{array}{l}\text { Ad Diper (Vice- } \\
\text { presidente) }\end{array}$ & Mestre & $\begin{array}{l}2007- \\
\text { atual }\end{array}$ & P26 & $\begin{array}{l}20 / 09 \\
/ 2012\end{array}$ & $58 \mathrm{~m}$. \\
\hline$\frac{\pi}{8}$ & $\begin{array}{c}\text { Entrevistado } \\
\text { PEeBA } 30\end{array}$ & ARA Agrícola & $\begin{array}{c}\text { Engenheiro } \\
\text { civil }\end{array}$ & $\begin{array}{l}2004- \\
\text { atual }\end{array}$ & P27 & $\begin{array}{l}02 / 10 \\
/ 2012\end{array}$ & $18 \mathrm{~m}$. \\
\hline$\frac{\frac{\pi}{0}}{\frac{5}{5}}$ & $\begin{array}{c}\text { Entrevistado } \\
\text { RNeCE } 31\end{array}$ & Coopyfrutas & $\begin{array}{l}\text { Engenheiro } \\
\text { agrônomo }\end{array}$ & $\begin{array}{l}2010- \\
\text { atual }\end{array}$ & P28 & $\begin{array}{l}11 / 10 \\
/ 2012\end{array}$ & $39 \mathrm{~m}$. \\
\hline ఱ & $\begin{array}{c}\text { Entrevistado } \\
\text { RNeCE } 2\end{array}$ & $\begin{array}{l}\text { Agrícola Famosa- } \\
\text { Ger. Com. de Exp. }\end{array}$ & Economista & $\begin{array}{l}2007- \\
\text { atual }\end{array}$ & P29 & $\begin{array}{l}18 / 10 \\
/ 2012\end{array}$ & $11 \mathrm{~m}$. \\
\hline
\end{tabular}

QUADRO 2 - Apresentação dos sujeitos entrevistados

Fonte: Elaboração dos autores (2012).

A pesquisa documental também é apropriada para esse tipo de estudo. Assim, os dados secundários (GODOY, 1995), impresso e digital, foram obtidos com os interlocutores nos momentos das entrevistas e nos sites governamentais, institucionais e das empresas pesquisadas.

A investigação bibliográfica se constitui por teses, dissertações e artigos relacionados ao polo Mossoró-RN/Icapuí-CE e o polo Juazeiro-BA/Petrolina-PE. O 
material disponível na versão digital foi analisado no ATLAS.ti, classificado pelo sistema como documentos de P30 a P45 (códigos atribuídos pelo software quando recebe arquivos).

Anterior à coleta de dados, foi realizado um estudo piloto na Brazil Melon, localizada em Mossoró-RN, com porte e estrutura agrícola semelhantes aos da Agro Melão. O gerente comercial foi entrevistado com o objetivo de aprimorar o roteiro de entrevista, construído com base no referencial teórico, e proporcionar experiências valiosas, aperfeiçoando a condução do diálogo para facilitar a coleta com os participantes da investigação (MERRIAM, 1998).

A realização do estudo piloto proporcionou benefícios, como: correção e reelaboração de algumas questões; identificação dos principais competidores do setor e de temas que não haviam sido contemplados; e informações que colaboraram na construção do roteiro de entrevista para os representantes de organizações relacionadas ao setor.

Após a realização do estudo piloto, um dos autores participou da Feira Internacional da Fruticultura Tropical Irrigada (ExpoFruit), em junho de 2012, para se aproximar e conhecer os interlocutores do setor.

Por fim, indica-se que as anotações sobre o estudo piloto e a coleta de dados primários (entrevistas) foram registradas no diário de campo digital, em arquivo do word. Dúvidas, discrepâncias das informações, reflexões, contatos de pessoas a serem contatadas, entre outros dados foram relatados no diário, colaborando na organização e indicando lacunas a serem preenchidas sobre o fenômeno (MERRIAM, 1998).

Preocupando-se com isso, adotou-se a análise de conteúdo (BARDIN, 2011) para identificar as conexões, códigos e categorias existentes nas transcrições das entrevistas. O software ATLAS.ti apoiou essa etapa da pesquisa. Uma fase da análise ocorreu simultaneamente à coleta dos dados, por ser fundamental para os estudos qualitativos (TAYLOR; BOGDAN, 1984).

Por fim, para alcançar o rigor científico, adotaram-se alguns critérios de validação e confiabilidade, a saber: triangulação, construção do corpus de pesquisa, descrição clara, rica e detalhada, feedback dos informantes (validação comunicativa), surpresa e reflexividade (PAIVA JÚNIOR; LEÃO; MELLO, 2011). 
Resultados

Os dados são apresentados em duas etapas. A primeira revela a presença das oportunidades em cada uma das quatro empresas para, em seguida, explanar sobre a análise cruzada dos casos.

\section{Agrícola Famosa (AF)}

A Agrícola Famosa é a maior exportadora internacional de melão, com registro fiscal no município de Icapuí-CE e produtora em 20.807 hectares. A empresa possui cinco fazendas próprias, com total de 14.999 hectares e oito arrendadas com 5.808 hectares (AGRíCOLA FAMOSA, 2012).

Trata-se de uma born global (RENNIE, 1993) fundada para exportar melão, em 1995. Esse posicionamento estratégico foi herdado pela experiência adquirida por um dos sócios-fundadores no tempo que geria sua trading company.

O processo de internacionalização da Agrícola Famosa está demarcado em quatro fases com treze eventos. A primeira se constitui por três eventos marcantes. Assim como a segunda, a terceira possui quatro, sendo a última representada por três deles. A figura 1 revela as oportunidades que foram aproveitadas ao longo da trajetória da empresa, subdividindo-se em dois tipos: as de origem internacional e nacional. 
\&F - Oportunidade $\{4-7\}$

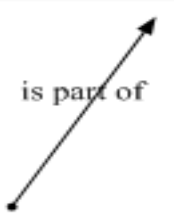

2: $\mathrm{AF}$ -

Oportunidade_internacio nal $\{16-16\}$

estou fazendo uma parceria,
a gente está fazendo uma
parceria com produtores que
já produzem lá há muito
tempo.

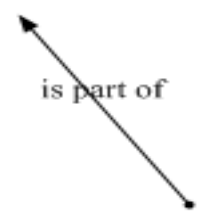

AF -

Oportunidade_nacional $\{14-16\}$

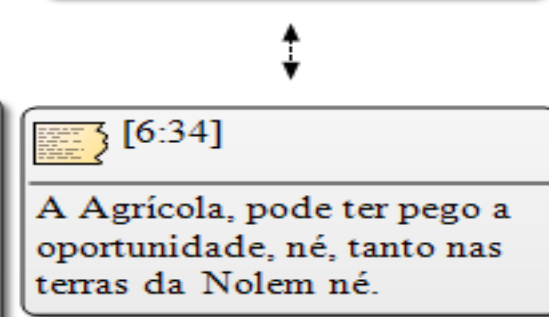

FIGURA 1 - Propriedades de oportunidade (Agrícola Famosa)

Fonte: Elaboração dos autores com ATLAS.ti (2012).

Aquelas encontradas no exterior foram arriscadas, favorecidas pelos contatos das redes de relacionamentos e passíveis de exploração devido aos recursos existentes na companhia, assim como serviram de fonte de desenvolvimento de recursos, resultado que fortalece a proposta de Schweizer, Vahlne e Johanson (2010). As nacionais foram também arriscadas, exigindo adaptação da Agrícola Famosa, com práticas inovadoras. Essa concepção foi identificada também nas pesquisas de Silveira e Alperstedt (2007) e Sohn, Lenzi e Kiesel (2004).

\section{Agro Melão (AM)}

A Agro Melão é considerada a segunda maior produtora de melão da região, com 1.000 hectares e fundada em setembro de 1997. O endereço fiscal, o escritório 
administrativo e parte da fazenda estão situados em Mossoró-RN. No Ceará existe outra unidade produtiva.

A empresa foi constituída para exportar, evidenciando um posicionamento de internacionalização influenciado pela experiência e formação profissional do fundador da firma. Trata-se de uma born global que desde o primeiro ano exporta (RENNIE, 1993). No início, exportava indiretamente via fornecimento para Del Monte, no quinto ano, em conjunto com uma associação e no oitavo ano de existência, mediante carreira solo.

Observam-se três fases no processo de internacionalização da Agro Melão. Três deles fazem parte da fase 1 , dois se configuram na segunda fase, enquanto que os últimos três estão na fase 3 .

Um aspecto interessante na Agro Melão é que a maioria das oportunidades identificadas e exploradas estava no domínio nacional. $\mathrm{Na}$ figura 2, evidencia-se essa constatação na observação do número existente em cada uma das categorias: oportunidade internacional (6) e oportunidade nacional (8).

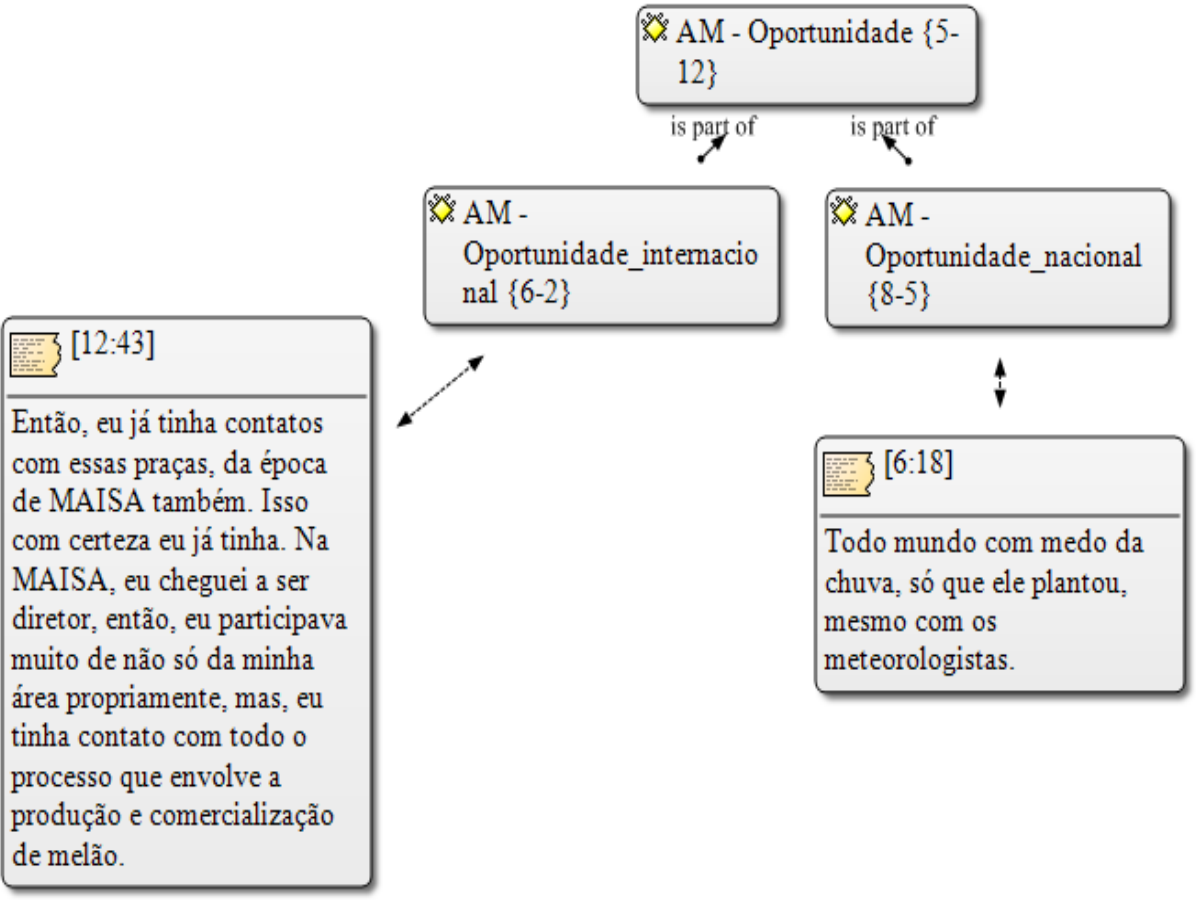

FIGURA 2 - Propriedades da oportunidade (Agro Melão)

Fonte: Elaboração dos autores com ATLAS.ti (2012).

É um achado intrigante e conduz a seguinte reflexão: sendo a internacionalização o escopo de análise, as oportunidades nacionais podem ser LEITE, Y. V. P.; MORAES, W. F. A.; SALAZAR, V. S. Tipos de oportunidades no empreendedorismo internacional. Revista de Empreendedorismo e Gestão de Pequenas Empresas, v. 4, n. 1, 2015. 
consideradas igualmente relevantes em detrimento das internacionais ou mais importantes? Tal discussão será tratada na seção de análise cruzada dos casos.

\section{Special Fruit (SF)}

A Special Fruit é reconhecidamente uma empresa de sucesso, com mais de 1.700 funcionários e 600 ha dedicados à manga e uva (SPECIAL FRUIT, 2012). Embora a pretensão inicial não tenha sido a internacionalização, a empresa pode ser classificada como uma born global (RENNIE, 1993) por ter se inserido rapidamente no comércio exterior. Três fases demarcam a biografia da Special Fruit, a primeira possui três eventos, a segunda quatro e cinco na terceira.

Semelhante à explanação das empresas anteriores, na análise contemplaram-se as oportunidades identificadas e exploradas pelo empreendedor. Isto posto, a figura 3 engloba a origem dessas oportunidades. Na Special Fruit, há uma concentração maior de oportunidades internacionais (KEUPP; GASSMANN, 2009), distinta da realidade da Agro Melão.

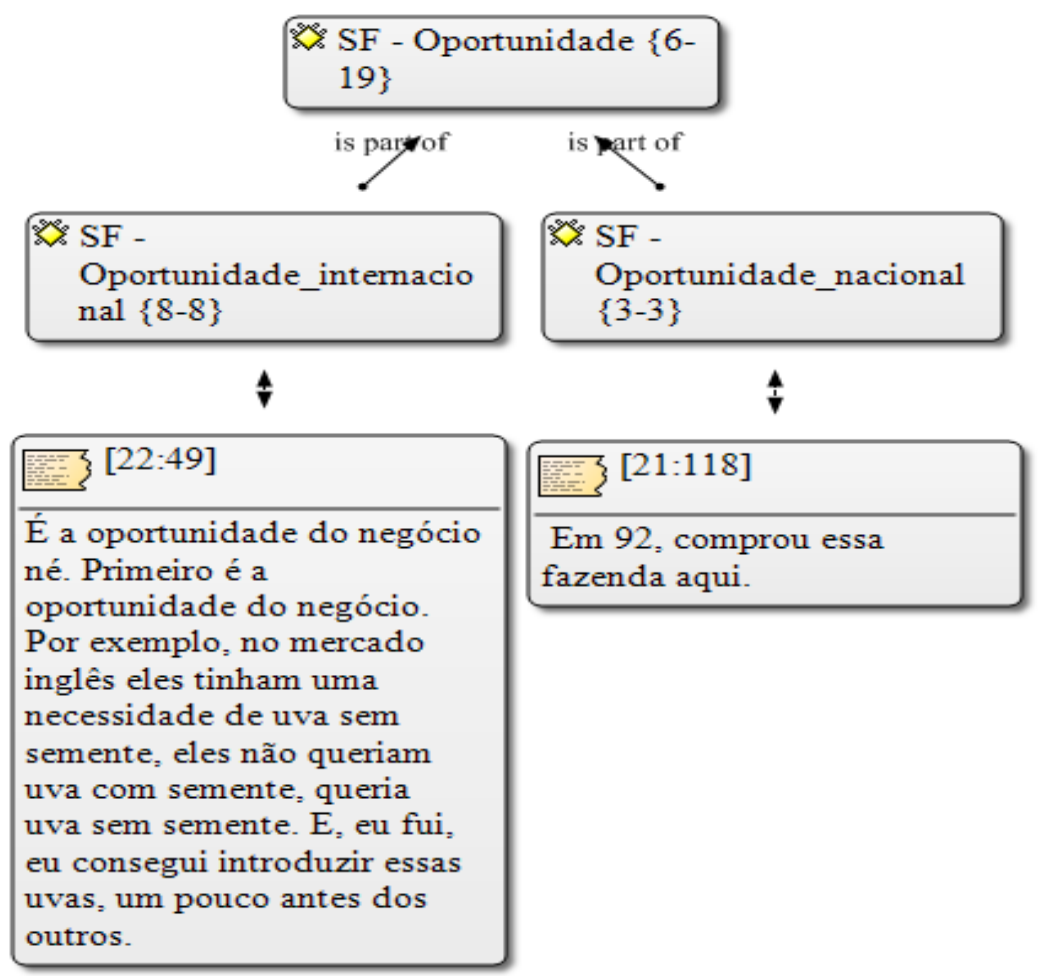

FIGURA 3 - Propriedades da oportunidade (Special Fruit)

LEITE, Y. V. P.; MORAES, W. F. A.; SALAZAR, V. S. Tipos de oportunidades no empreendedorismo internacional. Revista de Empreendedorismo e Gestão de Pequenas Empresas, v. 4, n. 1, 2015. 
Fonte: Elaboração dos autores com ATLAS.ti (2012).

Para explorá-las, o empreendedor assumiu riscos, por exemplo, da identificação da demanda por uvas sem sementes no mercado inglês que the resultou em investimentos vultosos em P\&D, visitas a fazendas e adaptação da produção. No caso das oportunidades nacionais, pode-se referir a uma delas que está apresentada no relato do líder sobre quando adquiriu a fazenda que desencadeou o desenvolvimento de recurso tangível, viabilizando a produção para atender ao mercado exterior.

\section{Ara Agrícola (ARA)}

Dentre as quatro empresas analisadas, a Ara Agrícola se distingue por ter menos tempo de existência e ser uma unidade estratégica de negócio da corporação familiar (BARNEY, 2002). A fazenda onde está localizada foi adquirida em 2004 com o objetivo de exportar uvas sem sementes (born global - RENNIE, 1993), único produto cultivado desde a fundação. $\mathrm{Na}$ safra, o empreendimento emprega aproximadamente mil funcionários (Entrevistada-PEeBA_16, 14:27; 14:54).

O pai era empreendedor agrícola no cultivo de algodão, em Limoeiro-PE, o histórico efetivo do proprietário da ARA Empreendimento remonta à época de estudante de engenharia civil, quando montou o primeiro negócio para prestar serviços na construção de apartamentos (Entrevistado-PEeBA_30, 27:8). Com a evolução da empresa, a companhia recifense se estabelece em diversas frentes, quais sejam: no desenvolvimento de projetos imobiliários, na fabricação fabril, agricultura e energia (ARA EMPREENDIMENTOS, 2012).

Esta pesquisa se atém à investigação da unidade localizada em Petrolina$\mathrm{PE}$, Ara Agrícola, reconhecida como uma das maiores exportadoras e mais sólidas da região (Entrevistado-PEeBA_17, 15:21). O processo de internacionalização da empresa possui duas fases e sete eventos. Três deles formam a primeira fase e a segunda é formada por quatro.

As oportunidades nacionais despontam como a maior parte das que foram exploradas. Para isso, o dirigente assumiu riscos, resultado que se assemelha aos 
da Agro Melão. Já as redes de relacionamentos favorecem e mitigam os riscos na identificação e exploração das oportunidades internacionais (figura 4).

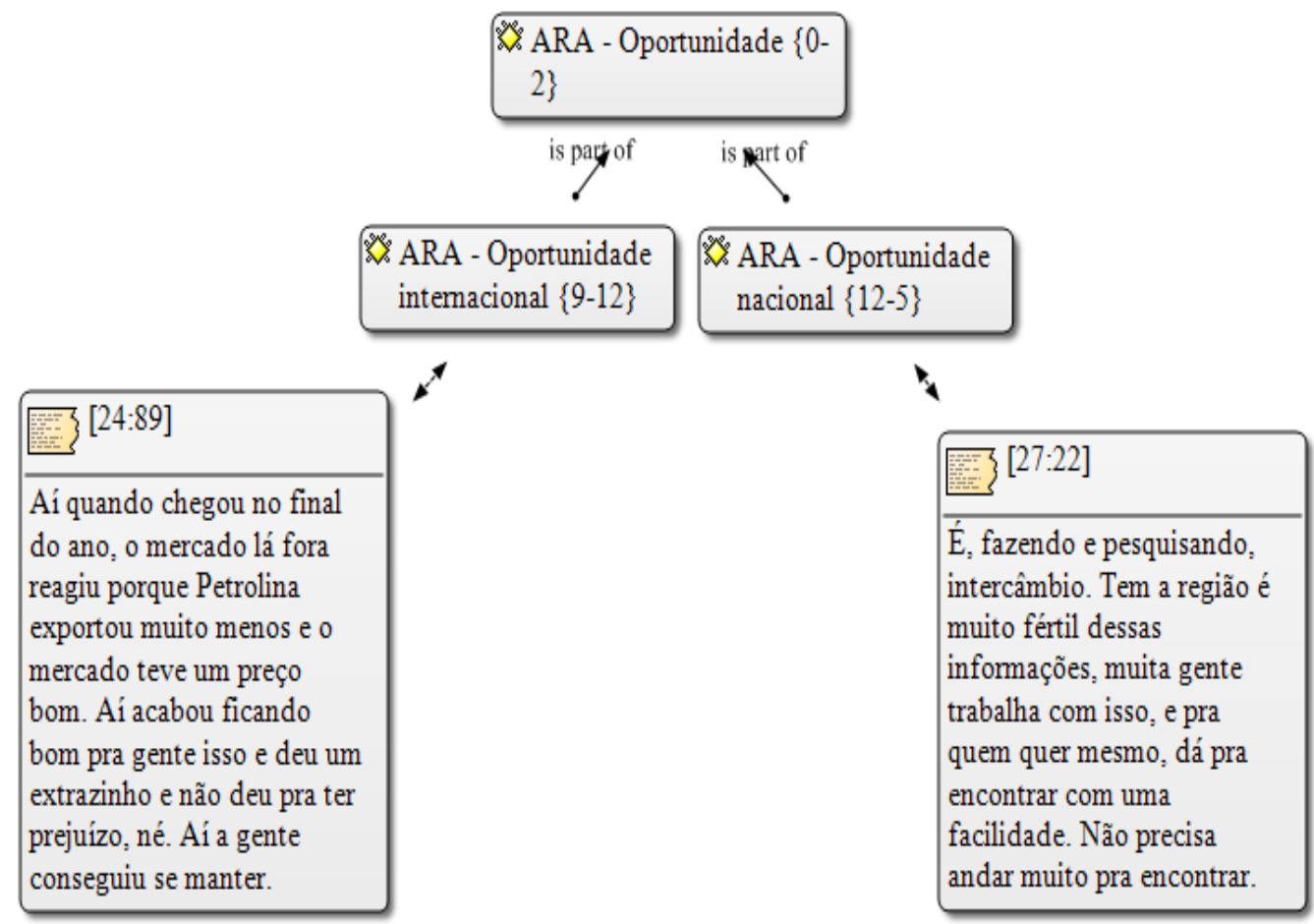

FIGURA 4 - Propriedades da oportunidade (Ara Agrícola)

Fonte: Elaboração dos autores com ATLAS.ti (2012

A rede informal SUNGROUP desempenha papel essencial nesse processo de empreender além da fronteira nacional. Nela, são acessadas oportunidades do ambiente nacional e exterior, essencialmente por meio da troca de informações e colaboração nas negociações (OVIATT; MCDOUGALL, 2005; SCHWEIZER; VAHLNE; JOHANSON, 2010).

\section{Oportunidade: análise cruzada dos casos}

A descoberta principal desta dimensão está no reconhecimento da relevância da exploração de oportunidades nacionais que colaboram no processo de internacionalização. Esta evidência conduz a retificar a nomenclatura, anteriormente definida por oportunidade internacional, passando agora para "oportunidade" que abarca as de origem nacional e internacional, denominando-se de tipos (quadro 3). 


\begin{tabular}{|l|c|c|c|c|}
\hline $\begin{array}{c}\text { TIPOS DE } \\
\text { OPORTUNIDADES }\end{array}$ & $\begin{array}{c}\text { AGRÍCOLA } \\
\text { FAMOSA }\end{array}$ & $\begin{array}{c}\text { AGRO } \\
\text { MELÃO }\end{array}$ & $\begin{array}{c}\text { SPECIAL } \\
\text { FRUIT }\end{array}$ & $\begin{array}{c}\text { ARA } \\
\text { AGRÍCOLA }\end{array}$ \\
\hline Internacional & $\checkmark$ & $\checkmark$ & $\checkmark$ & $\checkmark$ \\
\hline Nacional & $\checkmark$ & $\checkmark$ & $\checkmark$ & $\checkmark$ \\
\hline
\end{tabular}

QUADRO 3 - Definição das propriedades da Oportunidade

Fonte: Elaboração dos autores com ATLAS.ti (2012).

A análise de dados se ateve a identificar quais foram as oportunidades exploradas pelos líderes. A partir disso, pôde-se comprovar o previsto por Shane e Venkataraman (2000) ao defenderem que o empreendedor depreende esforços quando há expectativa de retornos elevados. Além disso, há uma transformação daquilo que está posto a todos, mas que para o empreendedor torna-se uma oportunidade, conforme proposto por Venkataraman et al. (2012).

Em todos os casos estudados, observa-se que a interpretação do contexto por parte desses sujeitos fez a diferença na identificação das oportunidades, aspecto sugerido na literatura (JONES; COVIELLO; TANG, 2011). Por exemplo, quando Nolem e a Del Monte divulgaram o fechamento da empresa, o empreendedor da Agrícola Famosa prontamente acessou os contatos internacionais para captar os clientes e procurou fazer negócio com as terras da Nolem.

Em 2011, o empresário da Agro Melão também conseguiu aproveitar o conhecimento e experiência para arriscar o plantio de melão dentro do período com maior risco de chuvas. Realizou e obteve resultados positivos. A chuva não apareceu, levando a empresa a ser a primeira a exportar naquele ano, conquistando mais espaço com os importadores.

Então, a interpretação e o monitoramento do contexto estão associados às escolhas estratégicas dos dirigentes (CHILD, 1972). A interpretação tem caráter subjetivo (CHILD; SMITH, 1987) e os dados mostram que acontece de modo semelhante no agronegócio. A escolha gerencial do empreendedor determina as chances dele explorar as oportunidades (PETERSON, 1988).

Além disso, observa-se, ao longo do processo de internacionalização, a natureza da oportunidade (ver figura 4). A oportunidade incide intermitentemente na 
internacionalização e a exploração das oportunidades mostra-se em determinados eventos marcantes do processo.

\begin{tabular}{|l|c|c|c|c|}
\hline \multicolumn{1}{|c|}{ DIMENSÃO } & $\begin{array}{c}\text { Agrícola } \\
\text { Famosa }\end{array}$ & Agro Melão & Special Fruit & $\begin{array}{c}\text { Ara } \\
\text { Agrícola }\end{array}$ \\
\hline Oportunidade & Intermitente & Intermitente & Intermitente & Intermitente \\
\hline
\end{tabular}

QUADRO 4 - Definição das propriedades da Oportunidade

Fonte: Elaboração dos autores com ATLAS.ti (2012).

Identifica-se que a oportunidade é uma dimensão relevante do empreendedorismo internacional. Tal achado está em consonância com Dimitratos e Plakoyiannaki (2003). Portanto, o papel do empreendedor é fundamental para identificar e viabilizar recursos para aproveitar as oportunidades.

\section{Considerações finais}

A pesquisa partiu da proposta de analisar os tipos de oportunidades no empreendedorismo internacional. Os dados permitem afirmar que existem dois tipos, são eles: o internacional e o nacional.

Acredita-se que as forças contextuais, a exemplo da crise internacional de 2008 e falência de concorrentes locais, levaram os dirigentes a não apenas explorarem oportunidades internacionais, como também a transformarem as oportunidades nacionais a favor da internacionalização. Esses achados ampliam o que vem sendo preconizado pelos cientistas de El quando reconhecem apenas as oportunidades de escopo internacional como essenciais.

Além dessa contribuição, a investigação revela a intermitência da dimensão, exploração de oportunidades, no processo de internacionalização. A dinâmica do ambiente interno e externo incita determinadas situações que levam o empreendedor a tomar decisões para manter a empresa competitiva no mercado internacional.

Diante de tal resultado, indica-se para estudos futuros, a análise da existência de possíveis classificações das oportunidades em cada um dos tipos. Ao conhecer as especificidades de oportunidades, os gestores poderão se preparar 
para aproveitá-las. Além disso, os estudiosos poderão fornecer mais conhecimento sobre o tema.

\section{Referências:}

AGRÍCOLA FAMOSA. Learn more about what our quality is made of. 2012.

ARA EMPREENDIMENTOS. Quem somos empresa. Disponível em: $<$ http://www.araempreendimentos.com.br/Empresa/index.html>. Acesso em: 28 out. 2012.

BARDIN, L. Análise de Conteúdo. São Paulo: Edições 70, 2011.

BARNEY, J. B. Gaining and Sustaining Competitive Advantage. 3. ed. New Jersey: Prentice-Hall, 2002.

BARTLETT, C. A.; GHOSHAL, S. Managing across Borders: New Strategic Requirements. Sloan Management Review, v. 28, n. 4, p. 7-17, verão 1987.

CHILD, J. Organizational structure, environment and performance: the role of strategic choice. Sociology, v. 6, n. 1, p. 2-22, 1972.

CHILD, J.; SMITH, C. The context and process of organizational transformation: Cadbury Limited in its sector. Journal of Management Studies, v. 24, n. 6, p. 565593, 1987.

COOMBS, J. E.; SADRIEH, F.; ANNAVARJULA, M. Two decades of international entrepreneurship research: what have we learned - where do we go from here? International Journal of Entrepreneurship, v. 13, n. 1, p. 23-64, 2009.

COVIELLO, N. E.; JONES, M. V. Methodological issues in international entrepreneurship research. Journal of Business Venturing, v. 19, n. 1, p. 485-508, 2004.

DIMITRATOS, P.; PLAKOYIANNAKI, E. Theoretical foundations of international entrepreneurial culture. Journal of International entrepreneurship, v. 1, n. 2, p. 187-215, 2003.

EISENHARDT, K. M. Building theories from case studies research. Academy Management Review, v. 14, n. 4, p. 532-550, 1989.

GODOY, A. S. Introdução à pesquisa qualitativa e suas possibilidades. Revista de Administração de Empresas, São Paulo, v. 35, n. 2, p. 57-63, mar./abr. 1995.

LEITE, Y. V. P.; MORAES, W. F. A.; SALAZAR, V. S. Tipos de oportunidades no empreendedorismo internacional. Revista de Empreendedorismo e Gestão de Pequenas 
HOSMER, L. T. T. The importance of strategic leadership. Journal of Business Strategy, v. 3, n. 2, p. 47-57, outono 1982.

IRELAND, R. D.; HITT, M. A. Achieving and maintaining strategic competitiveness in the $21^{\text {st }}$ century: the role of strategic leadership. Academy of Management Executive, v. 13, n. 1, p. 43-57, 1999.

JOHANSON, J.; VAHLNE, J. The internationalization process of the firm: a model of knowledge development and increasing foreign markets commitments. Journal of International Business Studies, v. 8, n. 1, p. 23-32, Spring 1977.

JOHANSON, J.; VAHLNE, J. The Uppsala Internationalization Process Model Revisited: from liability of foreignness to liability of outsidership. Journal of International Business Studies, v. 40, n. 9, p. 1411-1431, 2009.

JONES, M. V.; COVIELLO, N.; TANG, Y. K. International entrepreneurship research (1989-2009): a domain ontology and thematic analysis. Journal of Business Venturing, v. 26, n. 1, p. 632-659, 2011.

KEUPP; M. M.; GASSMANN, O. The past and the future of international entrepreneurship: a review and suggestions for developing the field. Journal of Management, v. 35, n. 3, p. 600-633, jun.2009.

KISS, A. N.; DANIS, W. M.; CAVUSGIL, S. T. International entrepreneurship research in emerging economies: a critical review and research agenda. Journal of Business Venturing, v. 27, n. 2, p. 266-290, mar. 2012.

LEITE, Y. V. P.; MORAES, W. F. A. Facetas do Risco no Empreendedorismo Internacional, Revista de Administração Contemporânea - RAC, Rio de Janeiro, v. 18, n. 1, p. 96-117, jan./fev. 2014.

MCDOUGALL, P. P. International versus domestic entrepreneurship: new venture strategic behavior and industry structure. Journal of Business Venturing, v. 4, n. 6, p. 387-400, 1989.

MDIC. Panorama do Comércio Exterior Brasileiro Janeiro-Dezembro 2010. Disponível em: $<$ http://www.mdic.gov.br//sitio/interna/interna.php?area=5\&menu=571>. Acesso em: 19 fev. 2011.

MERRIAM, S. B. Qualitative research and case study applications in education. San Francisco: Jossey-Bass, 1998.

MTIGWE, B. Theoretical milestones in international business: the journey to international entrepreneurship theory. Journal of International Entrepreneurship, v. 4, n.1, p. 5-25, 2006.

LEITE, Y. V. P.; MORAES, W. F. A.; SALAZAR, V. S. Tipos de oportunidades no empreendedorismo internacional. Revista de Empreendedorismo e Gestão de Pequenas 
NUMMELA, N.; SAARENKETO, S.; PUUMALAINEN, K. A global mindset: a prerequisite for successful internationalization? Canadian Journal of Administrative Sciences, v. 21, n. 1, p. 51- 64, mar. 2004.

OVIATT, B. M.; MCDOUGALL, P. P. Defining international entrepreneurship and modeling the speed of internationalization. Entrepreneurship Theory \& Practice, v. 29 , n. 5, p. 537-553, 2005.

PAIVA JÚNIOR, F. G.; LEÃO, A. L. M. S.; MELLO, S. C. B. Validade e Confiabilidade na Pesquisa Qualitativa em Administração. Revista de Ciências da Administração, v. 13, n. 31, p. 190-209, set./dez. 2011.

PETERSON, R. Understanding and encouraging entrepreneurship internationally. Journal of Small Business Management, v. 26, n. 2, p. 1-7, april 1988.

RENNIE, Michael W. Born Global. The McKinsey Quarterly, v. 4, p. 45-52, 1993.

SCHWEIZER, R.; VAHLNE, J. E.; JOHANSON, J. Internationalization as an entrepreneurial process. Journal of International Entrepreneurship, v. 8, n. 4, p. 343-370, 2010.

SEBRAE. Anuário do trabalho: na micro e pequena empresa 2010/1011. 2011. Disponível em: <http://www.dieese.org.br/anu/anuSebraeMicroPeqEmp/anuarioSebrae10-11.pdf>. Acesso em: 9 nov. 2012.

SHANE, S.; VENKATARAMAN, S. The promise of entrepreneurship as a field of research. Academy of Management Review, v. 25, n. 1, p. 217-226, jan. 2000.

SILVEIRA, P. A.; ALPERSTEDT, G. D. O Processo de Internacionalização de uma Empresa de Pequeno Porte do Setor Moveleiro do Oeste de Santa Catarina sob a Ótica do Empreendedor. In: III ENCONTRO DE ESTUDOS EM ESTRATÉGIA, São Paulo, 2007. Anais... São Paulo: 3Es, 2007.

SMIRCICH, L.; STUBBART, C. Strategic management in an enacted world. Academy of Management Review, v. 10, n. 4, p. 724-736, 1985.

SOHN, A. P. L.; LENZI, F. C.; KIEZEL, M. D. A Presença do Espírito Empreendedor no Processo de Formulação de Estratégias de Internacionalização da Datasul. In: XXVIII Encontro da ANPAD, Curitiba, 2004. Anais... Curitiba: EnAnpad, 2004.

SPECIAL FRUIT. Disponível em:<http://www.fazendaspecialfruit.com/>. Acesso em: 25 out. 2012.

STAKE, R. E. The case of case study research. Thousand Oaks: Sage Publications, 1995, p. 1-12.

LEITE, Y. V. P.; MORAES, W. F. A.; SALAZAR, V. S. Tipos de oportunidades no empreendedorismo internacional. Revista de Empreendedorismo e Gestão de Pequenas 
TAYLOR, S. J.; BOGDAN, R. Introduction to qualitative research methods: the search for meanings. John Wiley \& Sons. 2. ed. 1984, p. 123- 145.

VENKATARAMAN, S.; SARASVATHY, S. D.; DEW, N.; FORSTER, W. R. Reflections on the 2010 AMR decade award: whither the promise? Moving forward with entrepreneurship as a science of the artificial. Academy of Management Review, v. 37, n. 1, p. 21-33, 2012.

VERNON, R. International investment and international trade in the product cycle. Quarterly Journal of Economics, v. 80, n. 2, p. 191-207, 1966.

YIN, R. K. Estudo de Caso: planejamento e métodos. 2. ed. Porto Alegre: Brookman, 2001.

ZAHRA, S. A.; GEORGE, G. International entrepreneurship: the current status of field and future research agenda. In: HITT, M. A.; IRELAND, R. D.; SEXTON, D. L.; AMP, S. M. (Eds.) Strategic entrepreneurship, creating a new mindset. Oxford: Blackwell Publishers Oxford, 2002, p. 255-288.

' Os autores agradecem à Coordenação de Aperfeiçoamento de Pessoal de Nível Superior - CAPES - pelo financiamento desta pesquisa. 